\title{
Analisis Semiotika Logo Dagadu
}

\author{
Fitri Handayani, Ahmad Khairul Nuzuli \\ Institut Agama Islam Negeri Kerinci \\ Institut Agama Islam Negeri Kerinci \\ yhie0804@gmail.com
}

\begin{abstract}
The message conveyed can produce many meanings depending on the perspective of the recipient of the message. This is an attraction for the author to raise the topic of this article about the semiotic analysis of the dice logo. Reference sources used by the author are journal articles, books, and presentation materials using Pierce's semiotic analysis method. Based on the author's analysis, it is concluded that the Dagadu logo in the language of the young generation of Jogja means eyes, symbolizing the image of creativity, the world of designing, the world of design. Based on Javanese cultural treasures, the eyes are related to the word ma'rifat, meaning as a group of people who can provide benefits to the community and their environment. Dagadu is endeavored to be able to present its concern for the problems that exist in urban areas and tourism in Jogjakarta with an emphasis on prioritizing specifically on aspects of graphic design by combining local, regional humor, puns and the spirit of experimentation in the context of art and popular culture.
\end{abstract}

Keywords: Logo, Dagadu, Message, Semiotics

Abstrak. Pesan yang disampaikan dapat menghasilkan banyak makna tergantung dari perspektif penerima pesan tersebut. Hal ini menjadi daya tarik bagi penulis untuk mengangkat topik artikel ini tentang analisis semiotika logo dagadu. Sumber referensi yang digunakan oleh penulis adalah dari artikel jurnal, buku, dan materi presentasi dengan metode analisis semiotika pierce. Berdasarkan analisa penulis diambil kesimpulan bahwa logo dagadu dalam bahasa anak generasi muda Jogja berarti mata, melambangkan citra kreatifitas, dunia rancang dunia desain. Berdasarkan khasanah budaya Jawa, mata berkaitan dengan kata ma'rifat, bermakna sebagai sekelompok orang yang dapat memberikan manfaat bagi masyarakat dan lingkungannya. Dagadu diupayakan untuk dapat mempresentasikan kepedulian terhadap masalah yang ada di perkotaan dan kepariwisataan di Jogjakarta dengan penekanan Lebih mengutamakan secara spesifik pada aspek desain grafis dengan memadukan lokal, humor daerah, plesetan serta semangat eksperimen ke dalam konteks seni dan budaya populer.

Kata Kunci: Logo, Dagadu, Pesan, Semiotika

PENDAHULUAN

Komunikasi bukan cuma berfungsi bagaikan proses, komunikasi bisa berperan sebagai pembangkit arti (the generation of meaning). Pesan yang di 
informasikan tersebut bisa menciptakan banyak arti tergantung dari perspektif penerima pesan tersebut. Salah satunya merupakan bahasa komunikasi visual yang memiliki peranan berarti serta jadi faktor utama dalam mengantarkan pesan serta ilham yang nampak maupun yang tidak nampak dalam suatu logo. Logo merupakan satu stimuli visual yang berikan identiti kepada suatu industri dalam strategi menghadirkan suatu produk (Henderson, 2003).

Menurut Valentine dalam Ahmad, Syarwani \& Harapan (2014) "logo harus sesuai dengan minat pasaran produk yang ditawarkan, artinya logo produk harus disesuaikan dengan pasaran yang menjadi sasaran produk yang dikeluarkan, dalam hal ini stereotip budaya pun mengambil peranan yang penting, contoh logo Nike, Nike sebagai produk yang desain logonya sederhana berbentuk tanda, harus dapat mewakili produk yang ditawarkan." Dalam hal ini semiotik sebagai ilmu tentang tanda mempunyai prinsip, sistem, peraturan, dan prosedur-prosedur keilmuan yang khas dan baku dalam membentuk makna pesan yang akan disampaikan kepada konsumen. Pemaknaan dan semiotika terdapat tiga unsur utama yakni:" (1) tanda, (2) acuan tanda, dan (3) pengguna tanda. Tanda merupakan sesuatu yang bersifat fisik, bisa dipersepsi indra kita, tanda mengacu pada sesuatu di luar tanda itu sendiri, dan bergantung pada pengenalan oleh penggunanya sehingga disebut tanda" (Logo Sebagai Alat Komunikasi Visual, 2012)

Sebuah logo juga bersifat demikian, dimana logo yang baik dapat mencerminkan jenis usaha yang dikelola pemilik logo berdasarkan idiomidiom grafis yang telah dikenalkan ke publik. Bukan hanya pada bidang usaha atau perusahaan saja logo juga sering dijadikan perpustakaan untuk membuat logo instansi yang lebih menarik dengan makna yang tepat, contoh lainnya pembuatan logo menjadikan promosi terlihat lebih menarik dan lain-lain. Berdasarkan hemat penulis, penelitian tentang logo untuk tujuan kajian bidang perpustakaan belum pernah dilakukan sebelumnya dan termasuk 
kajian analisis tentang Dagadu jogja juga belum pernah dilakukan. Perbedaan penelitian ini dengan penelitian analisis logo lainnya yaitu menggunakan analisis Pierce tentang esensi tanda mengarah pada pembuktian bahwa setiap tanda ditentukan oleh objeknya dan dapat dianalisis melalui unsur budaya atau kebiasaan yang menjadi makna terkandung dalam logo tersebut.

Dengan demikian menurut penulisan kepustakaan juga harus bisa memberikan analisis yang tepat dalam pembuatan logo yang ada di Perpustakaan. Pada prinsipnya logo merupakan simbol yang mewakili sebuah instansi, perusahaan atau produk perusahaan. Selain dari logo Nike, logo Dagadu Jogja merupakan sebuah logo yang sangat unik menjadi ikon tersendiri untuk produk seperti kaos, sandal, craft dan produk lainnya di Jogjakarta, berdasarkan hal tersebut penulis tertarik untuk menganalisis bagaimanakah pemaknaan pesan atau semiotika dari logo Dagadu Djogdja?

Semiotika komunikasi visual merupakan memberikan suatu interpretasi terhadap semiotika, yakni semiotika dijadikan sebagai metode pembaca karya itu sendiri. Semiotika merupakan sebuah ilmu yang mempelajari tentang membaca tanda (sign), serta berfungsi untuk memproduksi makna. Tanda adalah sesuatu yang dapat berarti atau bermakna lain bagi tanggapan orang lain (Sumbo, 2009).

Pada analisis semiotika ini penulis menggunakan teori semiotika Pierce. Peirce berpendapat bahwa ada tiga unsur yang terkandung dalam tanda, yaitu representamen, objek, dan interpretan. Dari Ketiga unsur tersebut saling terkait atau berhubungan satu sama yang lain, adanya hubungan antara pengiriman tanda dan penerimaan tanda dapat disebut proses semiosis (Aini, 2013). Hubungan ketiga unsur tersebut dapat dibentuk dengan pola tanda sebagai berikut: 


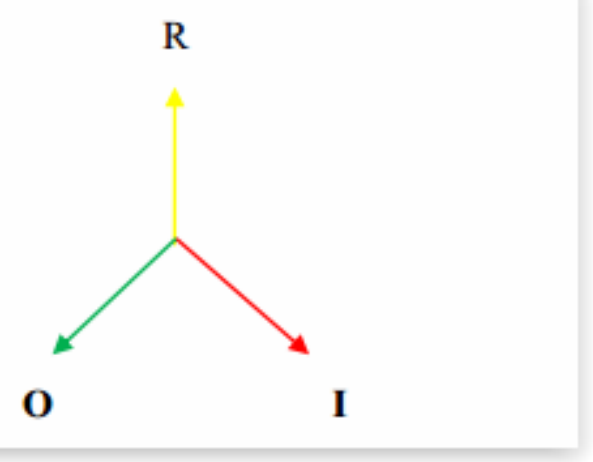

\section{Keterangan:}

$\mathrm{R}:$ Representamen (tanda)

O : Objek (sesuatu yang dirujuk)

I : Interpretan (hasil antara representamen dan objek)

Proses pemaknaan ciri pada Peirce menjajaki ikatan antara 3 arah anak panah, ialah representamen ataupun $\mathrm{R}$ (quallisign, sinsign, and legisign), objek ataupun $\mathrm{O}$ (icon, index and symbol) serta interpretan ataupun I ialah: rheme, decisign and argument. (R) ialah bagian dari ciri bisa dipersepsi secara raga maupun mental, dan merujuk pada suatu yang diwakili $(\mathrm{O})$, setelah itu (I) merupakan sesuatu proses yang bisa menafsirkan ikatan antara $(\mathrm{R}) \operatorname{serta}(\mathrm{O})$.

Representamen merupakan sesuatu raga ataupun modul yang mempunyai guna bagaikan ciri. bisa diinterpretasikan ialah pemaknaan ciri lain yang ekuivalen dengannya, atau sekumpulan interpretasi personal yang bisa dimaknai secara publik. Jadi pada hakikatnya, representamen serta interpretan bisa dikatakan bagaikan ciri, ialah sesuatu yang bisa mewakilkan suatu yang lain, cuma saja representamen muncul mendahului interpretan serta interpretan terdapat sebab terdapatnya representamen. Objek diwakilkan oleh ciri yang bertabiat "kenyataan" ataupun apa saja yang dikira terdapat. Maksudnya objek bertabiat konkret ataupun real, apalagi yang abstrak, imajiner, serta fiktif. Ciri serta denotatumnya Peirce memfokuskan ke dalam 3 aspek ciri ialah ikonik, indeksikal serta simbol. Ikonik merupakan sesuatu yang mewakili serta berperan bagaikan indikator seragam dengan wujud objeknya (nampak pada foto ataupun lukisan). Indeks merupakan suatu berperan bagaikan indikator dan 
mengisyaratkan petandanya, serta simbol ialah indikator yang berperan bagaikan indikator yang digunakan dalam warga (Ratmanto, 2004).

Dengan adanya artikel ini diharapkan penulis dapat memberikan kontribusi penambahan wawasan pustakawan dalam bidang promosi maupun kegiatan lainnya untuk dapat mendesain logo yang menarik, mewakili tujuan, visi dan misi serta dapat menjadikan logo sebagai sebuah media peningkatan daya tarik promosi di perpustakaan.

\section{HASIL DAN PEMBAHASAN}

\section{Dagadu Djogja}

Dagadu merupakan merek sebuah perusahaan yang digunakan oleh PT. Aseli Dagadu Djokdja di kota Yogyakarta. Dagadu pertama kali diluncurkan pada tanggal 4 Januari 1994 oleh 25 orang alumni mahasiswa arsitektur Universitas Gadjah Mada yang berjumlah. Sekelompok alumni tersebut memiliki minat akan kepariwisataan dan perkotaan dan berkreasi untuk menciptakan sebuah produk khas Yogyakarta. Counter awal Dagadu Djokja Lower Ground Malioboro Mall, Yogyakarta.

Faktor internal pendorong didirikannya PT. Aseli Dagadu Djokdja berasal dari minat masing-masing alumni tersebut yang kemudian didiskusikan dan muncul sebuah ide di bidang desain grafis untuk memproduksi kaos dengan pemasaran awalnya adalah mahasiswa. Produk awal lainnya selain kaos adalah t-shirt. Nama Dagadu pun awalnya muncul dari bahasa upatan slang khas Yoogyakarta dari salah seorang diantara mereka yaitu "Dagadu" yang berarti "matamu" setelah itu bahasa slank tersebut jadi nama merk produk mereka. Nama "Dagadu-Djokdja" yang mewakili bukti diri kelompok tersebut baru timbul serta digunakan dikala peluncuran perdana produk-produk di Lower Ground Malioboro Mall Yogyakarta, pada 9 Januari 1994. Adapun bahan-bahan mereka ialah "cinderamata alternatif dari Djokdja" (berbentuk kaus oblong, gantungan kunci, foto tempel, topi serta aksesoris lain yang muat rancangan grafis 
dengan tema- tema kepariwisataan serta area binaan kota Yogyakarta) yang awal mulanya ialah media penyaluran atensi serta idealisme dalam penyampaian gagasan- gagasan menimpa artifak, kejadian, bahasa, dan livingculture yang gayut dengan citra Yogyakarta.

\section{Pengertian Logo dan Simbol}

Logo merupakan sebuah gambar atau sketsa yang mengandung atau mewakili arti tertentu sebagai pengganti dari sebuah perusahaan, daerah, perkumpulan, produk, negara secara lebih sederhana (Kusrianto, 2009). John Murphy dan Michael Rowe seperti dikutip (Diah, 2014) menyatakan bahwa: "Setiap produk atau organisasi yang sukses, memiliki sendiri kepribadiannya dan kepribadian manusia yang kompleks, demikian juga kepribadian produk dan organisasi." Trademark dan logo sebuah produk dari suatu lembaga atau organisasi merupakan penampilan penyederhanaan dari tampilan kompleks dari produk tersebut, dapat di kontrol, dimodifikasi, serta setiap saat dapat dikembangkan. Berdasarkan pendapat ahli di atas dapat disimpulkan bahwa logo merupakan perwakilan sederhana dari sebuah lembaga atau produk yang dapat dikembangkan.

\section{Logo Sebagai Alat Komunikasi}

Logo merupakan komunikasi visual yang menggambarkan mewakili suatu lembaga atau institusi. Logo memiliki fungsi suntuk penyederhanaan ini dikemukakan oleh Seymour Papert seorang ahli mate-matika Swiss.

"In the mid of 1960s Seymour Papert, a mathematician who had been working with Piaget in Geneva, came to the United States where be co-founded the MIT Artificial Intelligence Laboratory with Marvin Minsky. worked with the team from Bolt, Beranek and Newman, Ied by W allace Feurzeig, that created the first version of logo in 1967” (Kridalaksana, 2001).

Logo merupakan bagian dari ilmu matematika, robot, music dan telekomunikasi termasuk juga bahasa dan filsafat ilmu. 


\section{Simbol}

Bagi Ratmanto (2004) menyatakan bahwa simbol berasal dari kata yunani "sym- ballein" yang berarti melemparkan bersama sesuatu (barang, perbuatan) yang berhubungan dengan sesuatu ilham. Sementara Herusanto dalam Diah (2014) mengatakan bahwa "symbolos", yang berarti ciri ataupun karakteristik yang memberitahukan suatu perihal kepada seorang. Umumnya simbol terjalin bersumber pada metonimi, ialah nama untuk barang lain yang berasosiasi atas yang jadi atributnya (misalnya Sang kaca mata buat seorang yang bercermin mata) serta metafora (metaphor), ialah konsumsi kata ataupun ungkapan lain buat objek ataupun konsep lain bersumber pada kias ataupun persamaan (misalnya kaki gunung, kaki meja, bersumber pada kias pada kaki manusia) (Kridalaksana, 2001). Simbol dapat mewakili produk atau lemabaga sebagai sarana atau media penyampai pesan kepada orang lain.

\section{Semiotika}

\section{Pengertian Semiotika}

Secara etimologis, Alex Sobur (2009) mengatakan bahwa istilah semiotika merupakan sebuah istilah yunani yakni "semion" dapat diartikan "tanda". Tanda tersebut dapat didefinisikan sesuatu atas dasar konvensi sosial yang dapat tergabung dari yang sebelumnya, dapat ditafsirkan mengandung makna sesuatu yang berbeda (Sobur, 2009). Sementara menurut Ardiansyah (2012) semiotika merupakan sebuah kajian tentang semiologi bisa berbentuk ciri serta arti dalam bahasa yang ada pada seni, media massa, musik serta seluruh perihal yang dibuat buat ditunjukkan kepada orang lain. Berdasarkan pendapat ahli di atas secara singkat pengertian semiotika adalah ilmu yang mempelajari tentang adanya tanda atau kode yang mengandung makna serta dapat diartikan berbeda oleh orang lain.

Pada kajian semiotika biasanya terdapat tiga permasalahan yang hendak diulas dalam analisis semiotik yaitu (Bungin, 2008): Pertama, permasalahan arti (the problem of meaning). Kedua, permasalahan aksi (the problem 
of action) ataupun pengetahuan tentang gimana mendapatkan suatu lewat pembicaraan. Ketiga, permasalahan koherensi (problem of coherence) yang menggambarkan bagaimana membentuk suatu pola pembicaraan masuk ide (logic) serta bisa dipahami (sensible).

\section{Jenis-Jenis Semiotika}

Semiotika dibedakan atas tiga jenis sebagai berikut (Nawiroh, 2015): Pertama, semiotika murni (Pure) Pure semiotic mengulas tentang filosofis semiotika, ialah berkaitan dengan metabahasa, dalam makna hakikat bahasa secara umum. Misalnya, ulasan tentang hakikat bahasa sebagaimana dibesarkan oleh Saussure serta pierce. Kedua, semiotika deskriptif (Descriptive) Descriptive semiotic merupakan lingkup semiotika yang mengulas tentang semiotika tertentu, misalnya sistem ciri tertentu ataupun bahasa tertentu, secara deskriptif. Ketiga, semiotika Terapan (Applied) Applied semiotic merupakan lingkup semiotika yang mengulas tentang pelaksanaan semiotika pada bidang maupun konteks tertentu, misalnya dengan kaitannya sistem ciri sosial, sastra, komunikasi, periklanan, serta lain sebagainya.

Tabel.1 Visualisasi logo Dagadu Djogja

\begin{tabular}{|l|l|l|}
\hline ANATOMI & \\
\hline JENIS LOGO & Logotype dan Logopictorial \\
\hline $\begin{array}{l}\text { ELEMEN } \\
\text { ESTETIS }\end{array}$ & Sans serif (tidak berkaki) \\
\hline
\end{tabular}




\begin{tabular}{|l|l|}
\hline TIPOGRAFI & \\
\hline BY-LINE & DAGADU Djokja \\
\hline JENIS HURUF & Futura \\
\hline GAYA LOGO & Combo Mark \\
\hline
\end{tabular}

Tabel. 2 Analisis semiotika logo Dagadu Djogja

\begin{tabular}{|l|l|}
\hline $\begin{array}{l}\text { ANALISIS } \\
\text { SEMIOTIKA } \\
\text { SEGITIGA } \\
\text { CHAKARA } \\
\text { PEIRCE SANDERS }\end{array}$ & \multicolumn{1}{|c|}{$\begin{array}{l}\text { HUBUNGAN } \\
\text { PENALARANNYA } \\
\text { DENGAN JENIS } \\
\text { PETANDANYA: }\end{array}$} \\
\hline QUALISIGN & $\begin{array}{l}\text { Wambar mata dengan warna hitam } \\
\text { melambangkan teknologi, kecanggihan, klasik, } \\
\text { konservatif,modern, tradisional atau } \\
\text { konvensional. Memiliki unsur kekuatan,dan } \\
\text { formalitas. Disisi lai hal itu dapat dikaitkan } \\
\text { dengan kejahtan, kematian, ketakutan dan } \\
\text { misteri. Warna hitam termasuk salah satu dari } \\
\text { warna netral yang hampir dapat dipastikan } \\
\text { cocok dengan warna lain apapun. } \\
\text { Memudahkan memberi kesan misteri pada } \\
\text { desain. } \\
\text { Bentuk mata merupakan berkaitan langsung } \\
\text { dengan nama 'Dagadu' itu sendiri serta ikon } \\
\text { mata dapat dikatakan sebagai sebuah idiom } \\
\text { yang menonjolkan citra kreativitas. Dagadu } \\
\text { dalam pandangan bahasa slang khas generasi } \\
\text { muda Yogyakarta bermakna 'matamu'. } \\
\text { Pandangan lain logo yang digunakan oleh } \\
\text { dagadu' adalah deskripsi ringkas dari merek }\end{array}$ \\
\hline
\end{tabular}




\begin{tabular}{|c|c|}
\hline & $\begin{array}{l}\text { dagang yang digunakan. Ikon mata ini } \\
\text { berkaitan erat dengan merefleksikan semangat } \\
\text { kreativitas. Jadi, Dagadu Djokdja dapat } \\
\text { mewakili pandangan kelompok akan sebuah } \\
\text { kreativitas yang tetap selalu dijaga dalam } \\
\text { sebuah kegiatan. } \\
\text { Kata DAGADU mempunyai satu corak ialah } \\
\text { gelap desigram Ghotic boldkn. Corak gelap } \\
\text { dalam tipografi DAGADU DJOGDJA } \\
\text { dimaksud dalam psikologis corak yaitu } \\
\text { kekuatan, seksualitas, kemewahan, kematian, } \\
\text { teka- teki, ketakutan, ketidak bahagiaan, } \\
\text { keanggunan. Dan terdapatnya penekan di bold } \\
\text { bagaikan kreativitas bersama buat kegiatan } \\
\text { ataupun seluruh perihal kehidupan yang } \\
\text { terdapat di Jogja. } \\
\text { Kata DjodgDja desigram corak tulisan gelap } \\
\text { tipe future semacam tipografi corak gelap yg } \\
\text { dipaparkan di atas. Sedangkan itu kata "DJOK } \\
\text { DJA" dalam padangan desainer Dagadu } \\
\text { Djokdja memiliki arti konotasi secara simpel. } \\
\text { Dalam imajinasi mereka, kata "DJOKDJA" } \\
\text { diambil dari konsep kirata basa ataupun } \\
\text { mengacu pada ilmu gothak- gathuk mathuk- } \\
\text { hingga kata "DJOK DJA" dimaksud dengan } \\
\text { dijok saja "DJOK" = dijok, "DJA" = saja) } \\
\text { ataupun dalam frame bahasa Indonesia } \\
\text { dimaknakan bagaikan "ditambah lagi." } \\
\text { Kata DAGADU Djogdja merupakan tipografi } \\
\text { yang memakai font Gothic Pro L serta ialah } \\
\text { karakteristik dari huruf Sans Serif ataupun } \\
\text { tanpa kait ataupun kaki ataupun ujung. Sans } \\
\text { serif ialah simbolisasi dari modern, } \\
\text { kontemporer serta efektif. }\end{array}$ \\
\hline SINSIGN & $\begin{array}{l}\text { Gambar mata yang menggambarkan adanya } \\
\text { kelompok yang selalu ingin untuk } \\
\text { berkreativitas dalam sebuah kegiatan dan terus } \\
\text { memberi nilai estetika pada hal-hal keseharian } \\
\text { atau hal-hal biasa secara sederhana merujuk }\end{array}$ \\
\hline
\end{tabular}




\begin{tabular}{|c|c|}
\hline & $\begin{array}{l}\text { akan hal-hal yang bahkan terlupakan oleh } \\
\text { masyarakat. } \\
\text { Kata DAGADAU DjogDja memakai tipografi } \\
\text { yang menggunakan font Gothic Pro L dan } \\
\text { merupakan ciri dari huruf Sans Serif atau } \\
\text { tanpa kait/kaki/ujung. Sans serif } \\
\text { disimbolisasikan sebagai modernitas, } \\
\text { kontemporer dan efisien. Dalam tipografi kata } \\
\text { "D diawal dan a diakhir" huruf berdekatan } \\
\text { merupakan simbol sikap bersahabat dan } \\
\text { kreativitas masyarakat Jogjakrta dalam } \\
\text { keseharian. Tipografi ini merefleksikan rasa } \\
\text { DAGADU DjogDja yang mengedepankan } \\
\text { estetika pada hal keseharian secara sederhana } \\
\text { dengan mengandalkan design grafis untuk } \\
\text { mengungkapkan tema yang telah disepakati. }\end{array}$ \\
\hline LEGISIGN & $\begin{array}{l}\text { Penulis mengartikan bahwa logo DAGADU } \\
\text { DjogDja selalu menempatkan semangat } \\
\text { kreativitas dalam setiap desain produk yang } \\
\text { dihasilkannya. Produk-produk yang } \\
\text { dihasilkannya sekilas tampak sederhana namun } \\
\text { unik, membumi dan selalu membuat } \\
\text { tersenyum, karena mencampurkan budaya } \\
\text { dengan desainnya. }\end{array}$ \\
\hline $\begin{array}{l}\text { HUBUNGAN } \\
\text { KENYATAAN } \\
\text { DENGAN JENIS } \\
\text { DASARNYA }\end{array}$ & \\
\hline ICON & $\begin{array}{l}\text { Bentuk Mata melihat dengan tulisan } \\
\text { DAGADU (Matamu) DjokDja pada logo. }\end{array}$ \\
\hline INDEKS & $\begin{array}{l}\text { Warna hitam dari logo tersebut } \\
\text { memperlihatkan adanya kekuatan budaya } \\
\text { tradisional serta misteri yang terkandung di } \\
\text { dalam aspek desain grafis termasuk budaya } \\
\text { populer dan netral. }\end{array}$ \\
\hline SYMBOL & $\begin{array}{l}\text { Ikon mata adalah idiom yang berkait erat } \\
\text { dengan citra kreativitas. Perwakilan dari } \\
\text { kelompok atau lembaga yang mempunyai } \\
\text { suatu aspek kreativitas dalam sebuah } \\
\text { kegiatannya. Lebih mengutamakan secara }\end{array}$ \\
\hline
\end{tabular}




\begin{tabular}{|c|c|}
\hline & $\begin{array}{l}\text { spesifik pada aspek desain grafis dengan } \\
\text { memadukan local,humor daerah, plesetan } \\
\text { serta semangat eksperimen ke dalam konteks } \\
\text { seni dan budaya populer. Strategi ini ditujukan } \\
\text { untuk meningkatkan daya jual produk. }\end{array}$ \\
\hline $\begin{array}{l}\text { HUBUNGAN } \\
\text { PIKIRAN DENGAN } \\
\text { JENIS } \\
\text { PETANDANYA }\end{array}$ & \\
\hline RHEME & $\begin{array}{l}\text { Bentuk mata yang mengisyratkan semangat } \\
\text { kreatifitas dari DAGADU DjokDja yg sllu } \\
\text { memberikan inovasi terhadap produknya } \\
\text { dengan memadukan unsur lokal, kedaerahan, } \\
\text { humor, klasik dengan kehidupan sehari-hari. } \\
\text { Mata pun menjadi sarana utama untuk } \\
\text { sightseeing, jalan-jalan sambil menikmati suasana } \\
\text { dan panorama kota. Maka Dagadu berharap } \\
\text { dapat mempresentasikan kepedulian terhadap } \\
\text { masalah perkotaan dan kepariwisataan di } \\
\text { Jogjakarta. } \\
\text { Logo Pictorial sebuah interpretasi kreativitas } \\
\text { dan profesionalitas yang tinggi dari perusahaan } \\
\text { DAGADU DjogDkarta untuk melakukan } \\
\text { inovasi tanpa melupakan tema dasar. } \\
\text { Logotype yang digunakan pada kata } \\
\text { DAGADU DjogDjakarta adalah wordmark } \\
\text { yang mengidentifikasikan suatu nama atau } \\
\text { merek. } \\
\text { Kata DAGADU DjogDjakarta memiliki jenis } \\
\text { font Sans Serif. }\end{array}$ \\
\hline DECISIGN & $\begin{array}{l}\text { Gabungan dari simbol ikon mata dan kata } \\
\text { DAGADU } \\
\text { DjokDja mencerminkan pandangan kelompok } \\
\text { yang selalu berusaha menempatkan kreativitas } \\
\text { sebagai aspek utama dalam setiap kegiatannya } \\
\text { sehingga menghasilkn produk yang berbaur } \\
\text { budaya, klasik, terpopuler dan tetap } \\
\text { membumi. }\end{array}$ \\
\hline ARGUMEN & Logo DAGADU DjogDja mencerminkan \\
\hline
\end{tabular}




\begin{tabular}{|l|l|}
\hline sebuah perpaduan kreatifitas seni Dan budaya \\
dengan menempatkan kretivitas sebagai aspek \\
utama, memberikan penekanan wacana \\
rancang grafis lewat desain huruf, type logo \\
dan warna hitam klasik yg netral. Selain \\
sebagai logo sekaligus juga merek dagang \\
perusahaan kaos oblong milik PT. Aseli \\
Dagadu Djokdja.
\end{tabular}

Kesederhanaan logo dagadu terlihat dari goresan elips yang berbentuk mata, dari pandangan generasi muda Jogja hal ini bermakna matamu sementara menurut pandangan lain hal tersebut merupakan deskripsi dari merek dagangan produk itu sendiri. Merek yang digunakan ini berkaitan dengan semangat kreativitas dan Dagadu Djokdja dapat mewakili makna kelompok yang selalu ingin semangat berkreativitas dalam setiap kegiatan sebagai aspek utamanya. Hal inilah yang menjadikan Dagadu Djokdja menjadi fenomenal karena selalu menempatkan semangat kreativitas dalam setiap produk yang mereka hasilkan.

Kesederhanaan produk ini juga membuat Dagadu Djogdja terlihat unik, membumi dan selalu membuat tersenyum, Ciri khas Dagadu Djokdja dapat dilihat sebagai berikut: (1) Desain sederhana, remeh, diambil dari halhal kecil biasana namun orang refleks untuk tersenyum melihatnya. (2) Menonjolkan ikon visual local sehingga produknya terkesan Jogja, sehingga produknya selalu menjadi oleh-oleh bagi wisatawan dan pelancong yang berkunjung ke Jogja. (3) Teks yang mengandung unsur humor dan plesetan, hal ini menjadi kekuatan membuat Dagadu Djokdja unik dari produk sejenis lainnya.

Pesan yang terkandung dalam Dagadu Djokdja lainnya adalah diharapkan logo tersebut dapat mempresentasikan kepedulian kelompok atau masyarakat terhadap kehidupan perkotaan serta pariwisata. Dagadu" sebagai kosa kata yang familiar dalam pergaulan generasi muda informal di 
Yogyakarta agar dapat menjadi perwakilan citra produk sebagai cinderamata khas Yogyakarta. Penyertaan kata "Djokdja" sesudah kata "Dagadu" semakin memperkuat citra local yang terkandung tersebut.

\section{PENUTUP}

Berdasarkan analisa di atas dapat diambil kesimpulan bahwa logo Dagadu DjokdJA merupakan pemaknaan dari matamu secara bahasa generasi muda Jogja bukan hanya sebagai sebuah logo. Mata yang berkaitan erat dengan citra kreativitas dunia rancang merancang. Pada khasanah budaya Jawa, mata ini disebut mripat, berdekatan dengan kata ma'rifat dapat diartikan yakni suatu kreativitas yang dapat bermanfaat bagi lingkungan dan masyarakat. Citra mata juga disebut dengan aktivitas sightseeing atau "cuci mata dengan berjalan-jalan keliling kota". Hal tersebut dapat merepresentasikan adanya kepedulian dari sekelompok masyarakat terhadap masalah yang ada di perkotaan dan kepariwisataan. "Dagadu" diharapkan agar dapat mewakili citra produk sebagai cinderamata khas Yogyakarta. Penyertaan kata "Djokdja" sesudah kata "Dagadu" semakin memperkuat citra local ini. Dagadu diupayakan untuk dapat mempresentasikan kepedulian terhadap masalah yang ada di perkotaan dan kepariwisataan di Jogjakarta dengan penekanan Lebih mengutamakan secara spesifik pada aspek desain grafis dengan memadukan lokal, humor daerah, plesetan serta semangat eksperimen ke dalam konteks seni dan budaya populer.

\section{DAFTAR REFERENSI}

Ahmad, Syarwani \& Harapan, E. (2014). Komunikasi antarpribadi. PT RajaGrafindo Persada.

Aini, A. N. (2013). Analisis Semiotik terhadap Novel Laskar Pelangi Karya Andrea Hirata sebagai Alternatif Bahan Pengajaran Sastra di SMA. Nosi, 1(2): 80-86. Malang: Mahasiswa Magister Pendidikan Bahasa Indonesia Universitas Islam Malang.

Andi. (2012). Logo Sebagai Alat Komunikasi Visual. http://is.uad.ac.id/blog/news/apakahlogo-uad-anda-sudah-benar/ Tentang Logo 
Bungin, B. (2008). Konstruksi Sosial Media Massa. Jakarta: Kencana.

Diah, L. S. (2014). Analisis Semiotika Logo Ades. Journal Imu Komunikasi,3(2).

Henderson, P. W. (2003). Building Strong Brands in Asia: Selecting the Visual Components of Image to Maximize Brand Strength. International Journal of Research in Marketing., 20, 297-313.

Kridalaksana. (2017). bttp:/ / el.media.mit.edu/Logofoundation/logo/Index.html 25 Mei 20177.

Kusrianto, A. (n.d.). 2019. Desain Komunikasi Visual.Jurnal Poltekes Jakarta. http://jurnal.poltekkesjkt2.ac.id/pengantar_desain_komunikasi_visual_ adi_kusrianto.pdf

Nawiroh, V. (2015). Semiotika dalam Riset Komunikasi. Ghalia Indonesia.

Ratmanto. (2004). Pesan: Tinjauan Bahasa, Semiotika, dan Hermeneutika. Mediator. Jurnal Komunikas, 5(1).

Sobur, A. (2012). Analisis Teks Media: Suatu Pengantar untuk Analisis Wacana, Analisis Semiotik, dan Analisis Framing. Bandung: Remaja Rosdakarya.

Sumbo, T. (2009). Semiotika Komunikasi Visual (3rd ed.). Jalasutra. 